\title{
The Value of Life Skills in Higher Education
}

\author{
Dr (Smt) Jyoti S.Kawalekar \\ Associate Prof. and Head of the Department of Botany, K.L.E.Society's R.L.Sc. Institute (Autonomous) \\ Belagavi
}

\begin{abstract}
Higher education is precarious to India's aspirations of evolving as a major player in the global knowledge economy. The global competitiveness of Indian industry and also its employment generation potential is clearly dependent on availability of required skills and trained personnel. Higher education should be both affordable and accessible to all. Emphasizes need to be given for greater adaptability in the higher education system so that it continues to provide the needed skills and trained workforce. Improving the skill development of stakeholders in higher education would contribute substantially to placing higher education as the foremost pillar on which our society is built. The academic world has serious doubts about where our society is going in many respects. However, the students going through higher education become the citizens who determine the nature of our society. Thus, higher education has a crucial opportunity to affect the future of our society through substantially improving the skill development of our citizens. The life skills approach is an interactive educational style that focuses on more than just information. To have an impact on behavior, information-based approaches need to be combined with attitudinal and interpersonal skills, known as 'life skills' that should aid to improve the changing of behavior. The life skills help learners to know and understand themselves better, live life more consciously and deliberately, attain personal satisfaction and fulfillment, and achieve their goals, personally and academically. Thus, this paper stresses the significance of life skills and life skill based education in improving the Quality of life. And understanding "The Value of Life Skills in Higher Education"

Keywords: Life Skills, Personal skills, academic skills, skill development, Higher Education,
\end{abstract}

\section{Introduction}

Higher education is precarious to India's aspirations of evolving as a major player in the global knowledge economy. The global competitiveness of Indian industry and also its employment generation potential is clearly dependent on availability of required skills and trained personnel. Higher education should be both affordable and accessible to all. Emphasizes need to be given for greater adaptability in the higher education system so that it continues to provide the needed skills and trained workforce.

Improving the skill development of stakeholders in higher education would contribute substantially to placing higher education as the foremost pillar on which our society is built. The academic world has serious doubts about where our society is going in many respects. However, the students going through higher education become the citizens who determine the nature of our society. Thus, higher education has a crucial opportunity to affect the future of our society through substantially improving the skill development of our citizens.

The life skills approach is an interactive educational style that focuses on more than just information. To have an impact on behavior, information-based approaches need to be combined with attitudinal and interpersonal skills, known as 'life skills' that should aid to improve the changing of behavior. The life skills help learners to know and understand themselves better, live life more consciously and deliberately, attain personal satisfaction and fulfillment, and achieve their goals, personally and academically.

The term 'Life Skills' refers to the skills you need to make the most out of life. These skills are usually associated with managing and living a better quality of life. They help us to accomplish our ambitions and live to our full potential. Any skill that is useful in your life can be considered as a life skill.

World Health Organization (WHO) in 1993 defined life skills as, "the abilities for adaptive and positive behavior that enable individuals to deal effectively with demands and challenges of everyday life. UNICEF defines life skills as, "a behavior change or behavior development approach designed to address a balance of three areas: knowledge, attitude and skills. "Therefore, life skills are a large group of psycho-social and interpersonal skills, which can help people, to make informed decisions, communicate effectively and develop coping and self-management skills that may help an individual to lead a healthy and productive life. Life Skills impart a supportive learning environment.

In a persistently varying environment, having life skills is an essential part of being able to meet the challenges of everyday life. The dramatic changes in global economies over the past five years have been matched with the transformation in technology and these are all impacting on education, the workplace and our home life. To cope with the increasing pace and change of modern life, students need new life skills such as the 
ability to deal with stress and frustration. Today's students will have many new careers over the course of their lives, with associated pressures and the need for flexibility.

Thus enhancing the skills development of youth in colleges and universities has become the need of the hour. In today's world, particularly in India, the future and relevance of Higher Education is intimately linked with Skills Development; the earlier Higher Education accepts this and acts accordingly, the better it is for the country and its growth. Skills Development is not an additional course that can be added to a university curriculum but it requires to be integrated into the training and education of a youth who will have to be readily employable and competent enough to run the operations of a company or business in India. A youth seeking job in the market today is expected to have appreciable life and soft skills which he has no clue about till s/he faces an interview. Higher Education does little to address the skills requirement of a youth raring to go into the world and make a mark.

\section{Understanding Life Skills - A Teacher's prospective}

Life skills include psychosocial competencies and interpersonal skills that help people make informed decisions, solve problems, think critically and creatively, communicate effectively, build healthy relationships, empathize with others, and cope with managing their lives in a healthy and productive manner. Essentially, there are two kinds of skills - those related to thinking termed as "thinking skills"; and skills related to dealing with others termed as "social skills". While thinking skills relate to reflection at a personal level, social skills include interpersonal skills and do not necessarily depend on logical thinking. It is the combination of these two types of skills that are needed for achieving assertive behavior and negotiating effectively. "Emotional" can be perceived as a skill not only in making rational decisions but also in being able to make others agree to one's point of view. To do that, coming to terms first with oneself is important. Thus, self-management is an important skill including managing/coping with feelings, emotions, stress and resisting peer and family pressure. Young people as advocates need both thinking and social skills for harmony building and promotion on issues of concern. The role of a teacher here is to provide ample opportunities and situations to the students so that they can acquire, process and structure these.

\section{Essential Life Skills in education}

Life without education is a life without opportunity. There is no definitive list of life skills. Certain skills may be more or less relevant to you depending on your life circumstances, your culture, beliefs, age, geographic location, etc. Different life skills will be more or less relevant at different times your life, for example: When at school or university, you'll need study skills; When buying a house, negotiation skills may be needed; You'll need to work on your employability skills to get a job; When you have a job, leadership and presentation skills may be useful, along with a whole host of other skills; When you start a family, time management and organizing skills are likely to become important. There will be times throughout your life when you'll need conflict resolution, stress-management and problem solving skills too. However, perhaps the most important life skill is the ability and willingness to learn. By learning new skills we increase our understanding of the world around us and equip ourselves with the tools we need to live a more productive and fulfilling life, finding ways to cope with the challenges that life, inevitably, throws at us. Life skills are not always taught directly but often learned indirectly through experience and practice. Life skill based education should start and it should at an early period of education and continue till the student completes his graduation .If we can start life skill based education in an earlier stage, before negative patterns of interaction and behavior have become established (WHO, 1994), it would be much more effective.

\section{The Ten core Life Skills as laid down by WHO are:}
1. Self-awareness
6. Problem Solving
2. Empathy
7. Effective communication
3. Critical thinking
4. Creative thinking
8. Interpersonal relationship
9. Coping with stress
5. Decision making
10. Coping with emotion

\section{Importance of Life Skill Education}

$>$ Life skills help youths to transit successfully from childhood to adulthood by healthy development of social and emotional skills.

$>$ It helps in the development of social competence and problem solving skills, which in turn help youths to form their own identity.

$>$ It helps to weigh pros and cons of the situation, hence, act as a mediator to problem behaviour.

$>$ It promotes positive social, norms that an impact the adolescent health services, schools and family. 
$>$ It helps adolescents to differentiate between hearing and listening and thus, ensuring less development misconceptions or miscommunications regarding issues such as drugs, alcoholism etc.

$>$ It promotes the development of positive self-esteem and teaches anger control.

The teachers in the present higher secondary and graduate classes are already overburdened with different tasks and they even have to 'rush' through portions to 'finish' the syllabus (Personal communication, teachers, 2012). In this context, the most effective methods to inculcate these skills like brain storming, collaborative learning and other time consuming methods may not be feasible to practice in a regular manner in our classrooms. But we cannot take it as an excuse for not providing training in life skills, which is very significant to their teenage as well as future life. Within the limitations of the present Indian classrooms, the teachers have to think creatively the means to inculcate these skills in our younger generation youthful learners, who are very delicate and brittle. There are ample opportunities in our present education system to incorporate life skills training. One way or the other, we can provide life skill education and training. A dedicated work force is the only necessary criterion. A purposeful and well planned improvisation of the current classroom transaction pattern, with provision for increased student participation and responsibility of learning could be a good beginning. Meaningful use of co-curricular activities could be a best venue for developing life skill. If we are able to do this much to our students, they will definitely learn the core life skills. It only requires a well thought out planning of class room and co-curricular activities. Once the students are competent in various life skills, they can easily deal with the external and internal issues which otherwise could pose threat to their healthy life patterns. The mastery over life skills could help them to deal effectively with these issues. When they reach adult hood, they would be well armed to deal effectively with the challenges of life and job.

But at present, many of us, we the teachers are "dumping" academic information over their students. The pressure from the family and the teaching pattern of our teachers would finally lead a student to think that academic excellence is the one and only aim of education. Academic performance has its own credit but it is not enough for a meaningful life. A meaningful life in the society demands all round development of each of its citizen. A mere academic excellence will not contribute much in this regard, unless it is blended with different life skills. This is possible only through empowered teachers. If a teacher wishes, he/she can develop a child in to a well-adjusted adult who is fit for the society.

Thus need of persistent teacher training programmes are also the need of the hour and the best venue to orient and empower teachers in this regard. This would help them to practice what new they have learned immediately on the target group. Hence training about the ways to impart life skills to students should be an integral part of all the in service programme like orientation and refresher programmes. Let the teachers be armed first. Then allow them to practice what they have learnt. We can hopefully wait for a better generation who are healthy both in mind and spirit.

\section{Conclusion}

Life skills are very important and integral part of educational system worldwide. Higher education has the potential to deliver skills and research for productivity and innovation. It is important to remember that Education with life skills is not another subject but it humanizes education. It helps to organize thinking and effort to achieve a goal. Once an Action Plan has been developed, especially in the curriculum, it can be developed spirally, in depth and width. A lot of thought requires to be given on how to bring in life skills education into the mainstream curriculum. Our educational policies and the subsequent curriculum frameworks all along have emphasized the need for Life skill Education. It is also true that in order to be effective; there must be clearly defined and definite focus, direction and commitment for fostering life skills. These can be acquired every moment and every day of our lives. Life skills are essentially those abilities that help promote overall wellbeing and competence in young people as they face the realities of life. They are the beginning of wisdom which focuses on behavior change or developmental approach designed to address a balance of three areas- knowledge, attitude and skills. These skills enable individuals to translate knowledge, attitude and values into actual abilities-i.e. what to do and how to do it, given the scope and opportunity to do so. Promoting efficient life skills training programme in higher education would thereby be an ode to the youth in the country. It would be a way of empowering youth to build their lives and their dreams. It would be a means of handholding them through the critical stages in their life and helping them tap their potential to the fullest. Thereby, it is hoped that the current education system with its oppressive rigidity would open up and make life skills education a part of its mainstream curriculum. This would enable the country to build individuals who believe in themselves, who are efficient leaders and administrators, who are able to understand their potentials and achieve them. 


\section{References}

[1]. WHO. (1994). Life Skill Education for Children and Adolescents in Schools. Programme on mental health. Geneva: WHO

[2]. UNICEF. (2011a). Which Skills are Life Skills. Retrieved July 02, 2012 from

[3]. www.unicef.org.

[4]. Indian education http://www.mapsofindia.com/india-education.html

[5]. Shiela Ramakrishnan, (2010), Life skills education in schools, in 'Teacher plus- a magazine for the contemporary teacher.

[6]. http://www.teacherplus.org/2010/february-2010/life-skills-education-in-our-schools 